\title{
Paragrafação e argumentação em cartas de reclamação escritas por alunos do ensino fundamental
}

\section{Paragraphing and argumenting in letters of claim written by elementary school students}

Leila Nascimento da Silva

Universidade Federal Rural de Pernambuco, Recife, Pernambuco / Brasil

leilansufrpe@gmail.com

Telma Ferraz Leal

Universidade Federal de Pernambuco, Recife, Pernambuco / Brasil

tfleal@terra.com.br

Resumo: Neste artigo, busca-se verificar como a paragrafação e a argumentação se realizam em diferentes etapas do ensino fundamental. Participaram da pesquisa cinco turmas do ensino fundamental $\left(3^{\circ}, 5^{\circ}\right.$ e $7^{\circ}$ anos), da Rede Pública de Pernambuco, que vivenciaram uma sequência didática relacionada ao gênero "carta de reclamação". Analisaram-se 37 textos produzidos ao final das atividades. Os textos foram agrupados pela relação entre a paragrafação e a argumentação. Os resultados sinalizaram que os alunos são capazes de construir parágrafos e atribuir um sentido lógico a essa divisão. Em relação à argumentação, muitos conseguiram produzir justificativas e alguns até chegaram a contra-argumentar. No entanto, até mesmo aos alunos que já tenham um domínio maior nessa esfera - de forma intuitiva ou não - a escola precisa garantir um tempo pedagógico para ajudá-los a avançar em seus conhecimentos e a superar suas dificuldades.

Palavras-chave: paragrafação; argumentação; cartas de reclamação. 
Abstract: In this article we to verify how the paragrafation and the argumentation take place in different elementary school. Five classes of elementary school (3, 5 and 7 years) of Pernambuco's Public Network attended this research and experienced a didactic sequence involving gender "letter of complaint". 37 texts produced at the end of the activities were analyzed. We grouped the texts by the relationship between the paragraphing and argumentation. The results signaled that the students are able to construct paragraphs and assign a logical sense of this division. Regarding the argument, many are able to produce justifications and some of them even to argue. Even the students demonstrating to possess such knowledge, either intuitively or unconsciously, the school needs to ensure a teaching time to help them advance in their knowledge and overcome their difficulties.

Keywords: paragraphing; argumentation; complain letter.

Recebido em 30 de novembro de 2016.

Aprovado em 19 de abril de 2017.

Há muito se tem discutido a importância de um trabalho mais sistemático com textos em sala de aula. Essa sistematização passa a ser considerada como ponto de partida para que os alunos sejam estimulados a refletir sobre vários aspectos referentes a sua língua materna, importantes na formação de bons leitores e produtores de textos. Assim sendo, todas as dimensões textuais que fazem parte das ações de linguagem - entre elas, a paragrafação - precisam ser objeto de estudo na escola.

De acordo com os estudos desenvolvidos por Bessonnat (1988), o parágrafo em si não é considerado, por muitos estudiosos, como uma unidade semântica pertinente do texto que teria seu lugar na hierarquia canônica (palavra-frase-texto). Por isso, quando as gramáticas de texto sentem a necessidade de tomar uma unidade maior que a frase, geralmente acabam não usando a noção de parágrafo, mas determinam unidades mais largas como sequências, macroestrutura ou episódio.

Por outro lado, quando o parágrafo é tomado para análise, afirma o supracitado autor, quase sempre é tratado isoladamente, gerando um problema de articulação do texto. Mesmo assim, "o parágrafo parece ser um dado textual aceito por todos e raramente questionado em si mesmo." (BESSONNAT, 1988, p. 81). 
Por considerarmos a habilidade de paragrafar relevante, buscamos verificar como a paragrafação e a argumentação se realizam em diferentes etapas do ensino fundamental. Na primeira parte do texto, discutiremos a paragrafação. Logo em seguida, o foco será a argumentação, mais especificamente o gênero argumentativo "carta de reclamação". Por fim, apresentaremos informações metodológicas da pesquisa realizada e os principais resultados da análise realizada.

\section{Estudos sobre paragrafação}

Para melhor discutirmos o tema do nosso artigo, buscamos nos apoiar em estudos teóricos e práticos que pudessem contribuir, de alguma forma, para compreendermos como a paragrafação se caracteriza, qual a relação entre a habilidade de paragrafar e o desenvolvimento da competência leitora e a formação de escritores experientes e como a paragrafação é apropriada pelas crianças. Essas reflexões iniciais nos permitem também tecer algumas breves considerações sobre o ensino da paragrafação.

Assim, no primeiro movimento de escrita desta seção discutiremos as possíveis relações entre leitura, escrita e paragrafação. Em seguida, apresentaremos dados de pesquisas que nos ajudam a melhor compreender a apropriação da paragrafação pelas crianças e a pensar sobre seu ensino.

\subsection{Estudos sobre paragrafação na leitura e na escrita}

Ao ler um texto, o leitor tem o desafio de tentar desvendar o sentido pretendido pelo autor e, com base nisso, estabelecer suas próprias relações, construindo outros sentidos possíveis. Nesse movimento, o texto, material concreto dessa interação, terá grande relevância. Para Kato (1995, p. 72), "o texto-produto é visto como um conjunto de pegadas a serem utilizadas para recapitular as estratégias do autor e através delas chegar a seus objetivos". Assim, entender o porquê de o autor ter organizado o texto de determinada forma, descobrir as relações que ele quis estabelecer entre as partes do texto, perceber o encadeamento das ideias conseguido é fundamental nessa construção de sentidos.

Notamos, portanto, que há uma íntima relação entre parágrafo e leitura. Bessonnat (1988) argumenta que há ao menos três funções básicas do parágrafo, e todas elas estão relacionadas à leitura. São elas: 1) facilitar a leitura; 2) programar a leitura; 3) dialogar (escritor e leitor). 

esclarece:

Sobre a primeira função sinalizada, Bessonnat (1988, p. 85)

A distribuição em parágrafos é um instrumento que facilita a leitura:

- A alínea assinala ao leitor que este acaba de tratar de uma unidade de sentido e que vai passar a uma próxima unidade .

- A alínea permite ao olho descansar e gravar as informações contidas no parágrafo anterior antes de tratar do conjunto seguinte.

Assim, os parágrafos ajudam o leitor na tarefa de descobrir as unidades de sentido de um texto, de armazenar as informações e, ainda, proporcionam uma pausa (pequena) para descanso durante a leitura.

A segunda função - programar a leitura - se configuraria como um meio de quebrar a organização linear do texto (leitura frase por frase): "no quadro de uma progressão temática derivada, os parágrafos se constituem em muitas gavetas sucessivas, anunciadas pelo tema geral inicial, autorizando uma leitura tabular e não simplesmente linear" (BESSONNAT, 1988, p. 85). É preciso, então, entender esses blocos de sentidos e relacioná-los. Essa divisão do texto e o estabelecimento de ligações entre suas partes não se dá de forma aleatória. O leitor/escritor precisa encontrar uma lógica para tudo isso, conforme salienta também Abarca e Rico (2003):

Para que o processo de ligação se realize adequadamente, o leitor/ escritor não deve ligar as frases do texto de qualquer maneira, mas deve-se ligá-las de forma que se vá construindo ao mesmo tempo o que Van Dijk e Kintsch (1983) chamam de macroestrutura do texto, isto é, uma estrutura hierárquica a partir das relações semânticas entre as ideias do texto (p. 142).

Como é possível perceber, todo esse movimento é, sobretudo, dialógico, fruto de uma negociação entre escritor e leitor. Acreditamos que, ao elaborar um texto, o escritor lança mão de vários recursos para indicar possíveis sentidos textuais que precisam ser construídos pelo leitor. O leitor, por sua vez, apoia-se nas pistas deixadas pelo autor do texto para fazer essa construção. Por isso, atualmente, segundo Yunes, a leitura é considerada um processo interativo entre leitor e escritor: 
Cada texto constitui uma proposta de significação que não se acha fechada e inteiramente concluída, porque se destina ao outro, no caso, o leitor. O sentido se dá no encontro dos olhares de um e outro, autor/leitor e leitor/autor. Porque cada um carrega seus acervos e repertórios que vão se cruzar e atualizar no ato da leitura (YUNES, 2009, 53).

A terceira função de um parágrafo, destacada por Bessonnat (1988), é justamente a de favorecer o diálogo entre esses sujeitos da interação. Apoiando-se nas ideias de Bakhtin, o referido autor comenta que os parágrafos seriam como respostas sucessivas aos questionamentos do interlocutor (fictício) do texto. Para reforçar sua posição, ele recorre a esta citação de Bakhtin (2002, p.141):

Indo cada vez mais na essência linguística dos parágrafos, nós nos convenceremos de que, em alguns de seus traços essenciais, eles são análogos às replicas de um diálogo. São, de uma certa forma, diálogos enfraquecidos e transformados em enunciaçõesmonólogos. Na base da divisão do discurso em partes, denominadas parágrafos na sua forma escrita, encontra-se o ajustamento às reações previstas do ouvinte ou do leitor. Quanto mais fraco o ajustamento ao ouvinte e a consideração das suas reações, menos organizado, no que diz respeito aos parágrafos, será o discurso.

Fortalece-se, portanto, a ideia de que um texto paragrafado colabora com o leitor, uma vez que permite um melhor acompanhamento do desenvolvimento das ideias, em seus diferentes estágios. Os parágrafos, então, podem ser entendidos como prateleiras que dividem uma sequência de informações, organizando-as de forma lógica.

Da mesma forma que encontramos contribuições importantes para o leitor, compreender o papel do parágrafo também se torna fundamental para o escritor. Como já ressaltamos anteriormente, sempre escrevemos pensando em veicular determinado sentido para nosso texto e, para tanto, tomamos diversas decisões, inclusive em relação à melhor forma de organizá-lo. Schneuwly (1988), ao formular sua teoria sobre os processos de produção textual, trata dessas tomadas de decisões e sobre as operações mentais envolvidas no ato de escrever um texto.

Para esse autor, a paragrafação seria uma habilidade relacionada ao processo de textualização, responsável pela progressão do conteúdo temático do texto e pela construção das relações de continuidade, de ruptura ou de contraste dentro deste. 
Seriam três tipos de operações que fazem parte da textualização e que visam estabelecer as articulações hierárquicas de um texto: as operações de coesão, as de conexão/segmento e as de modalização. Interessa-nos, aqui, destacar as operações de coesão e de conexão/ segmentação, pois elas estão intrinsecamente ligadas ao nosso objeto de estudo.

Essas operações seriam relativas justamente às estratégias de segmentar o discurso em partes, o que também pode ser reconhecido como uma operação de articulação, pois, ao segmentarmos as partes, salientamos unidades a serem articuladas.

Para esclarecer um pouco mais o que seriam essas operações de conexão/segmentação, Schneuwly (1988, p. 40) comenta:

A característica comum das operações de conexão/segmentação é, por um lado, "pontuar" o discurso, dividi-lo em partes e, ao mesmo tempo, funcionar como "cimento" que rejunta as unidades atomizadas resultantes da referenciação; por outro lado, articular essas unidades ao contexto. Sua característica formal é de agir sobre os núcleos predicativos, distribuindo-se, em consequência, no nível predicativo.

Para o supracitado autor, existem diferentes tipos de marcas para separar as unidades/partes do texto. Inicialmente, ele faz referência às marcas que separam grandes blocos de enunciados, tais como os subtítulos, os boxes, a mudança de página. Depois, cita também as marcas que separam as unidades menores do texto (pontuação, marcadores gráficos diversos, operadores argumentativos), assim como os processos de subordinação e coordenação entre proposições.

Bessonnat $(1988$, p. 93) também fala sobre essas relações de conexão/segmentação do texto, mas reflete especificamente sobre o papel dos parágrafos para essa articulação. Para ele, temos dois níveis de análise:

a articulação local: ou como se opera a passagem de um parágrafo para o outro.

- apertando - ou alargando o tema.

- com ruptura ou reprise do tema

- conforme uma estrutura de questão - resposta, de oposição, de paralelismo... 
a articulação global: ou como se opera a distribuição geral do texto em parágrafos

- o grau de segmentação do texto

- a distribuição dos parágrafos em função da progressão temática.

Outro aspecto importante referente às operações de conexão/ segmentação é a estreita ligação entre a divisão do texto em parágrafos e o ato de pontuar. Schneuwly (1988) lembra que essas duas ações têm o objetivo de delimitar ou segmentar as unidades textuais. É importante lembrar que a utilização do sistema de pontuação e a organização do texto em parágrafos funcionam em dependência estreita com outros níveis e tipos de operação. Ao pontuar e construir parágrafos, o escritor leva em conta o possível destinatário de seu texto e o objetivo da atividade de linguagem em curso, o gênero discursivo adotado para a situação interativa, o planejamento geral do texto e, finalmente, o sentido que pretende dar ao seu escrito.

Constatamos, portanto, que a paragrafação é uma habilidade importante que precisa ser apropriada pelas crianças paralelamente ao estudo dos diversos gêneros textuais. No tópico a seguir, discutiremos os dados de pesquisas que nos trazem informações pertinentes sobre o desenvolvimento das crianças em relação à paragrafação.

\subsection{Investigações sobre a paragrafação na escrita da criança}

Conhecer o processo pelo qual passam as crianças com relação ao ato de paragrafar torna-se um instrumento valioso para o professor na busca por realizar mediações pertinentes. Constatamos, no entanto, que são poucos os estudos que se dedicaram a estudar essa questão. Aqui, apresentaremos os dados de algumas pesquisas cujos resultados se convertem em informações importantes sobre as capacidades das crianças relacionadas à paragrafação.

Um dos estudos que encontramos foi o realizado por Moraes (1999), no qual a autora realizou uma intervenção pedagógica e acompanhou o desenvolvimento dos alunos, ao longo desse processo. $\mathrm{O}$ foco do trabalho foi nos textos narrativos (ênfase nas histórias, contos e lendas). Especificamente, a autora buscou caracterizar os diferentes modos de marcação gráfica, identificar os marcadores sintáticos mais usuais no encadeamento dos parágrafos e promover reflexão sobre a eficácia de um modelo pedagógico que priorize o texto, sua análise e construção. 
Participaram como sujeitos vinte e oito alunos de uma escola pública do Recife, que frequentavam uma $2^{\mathrm{a}}$ série. Tratava-se de uma turma bastante heterogênea, com alunos entre 9 e 16 anos e boa parte repetente. Desses, sete alunos estavam em níveis não alfabéticos, onze conseguiam ler apenas palavras de estrutura silábica simples (Consoante + Vogal), e dez alunos liam frases e pequenos textos, mas apresentavam dificuldades de compreensão. A intervenção realizada ocorreu durante o ano letivo de 1998 e os primeiros meses de 1999. Havia um trabalho sistemático de leitura e produção de textos, além de um trabalho voltado para a apropriação do sistema de escrita alfabética.

Nas aulas, eram analisados com os alunos os elementos que compõem os textos, os efeitos de sentido, as ideias-chave e os marcadores coesivos presentes na superfície textual. Também eram realizadas perguntas relacionadas à paragrafação, tais como: "Por que o autor começou a escrever afastado do início do texto? É preciso colocar um ponto no fim de cada parágrafo? Quais palavras iniciam cada parágrafo? Todos os parágrafos têm o mesmo tamanho? O autor dá sempre a mesma informação em todos os parágrafos?" (MORAES, 1999, p. 40). Além disso, houve vários momentos de produção nos quais os alunos reescreveram histórias, lendas e contos trabalhados em sala pela pesquisadora.

Os textos escolhidos para análise foram construídos em seis atividades diferentes de produção textual. Moraes fez uma análise mais minuciosa das produções de quatro alunos e pôde acompanhar de perto sua evolução.

Como principais resultados, a autora pôde ratificar que a constância e a diversificação de textos, em sala de aula, assim como a exploração de elementos que os compõem são, sem dúvida, relevantes para o amadurecimento cognitivo do aprendiz em relação à produção de textos.

Também pôde verificar que, após a intervenção, algumas crianças passaram a compreender o parágrafo como unidade de composição do texto. No início, o aluno 1 não conseguiu escrever nada; o aluno 2 produziu um texto ilegível; o aluno 3 escreveu um pequeno texto, sugeriu um título e iniciou a escrita afastada da margem esquerda, porém não utilizou nenhuma pontuação e apresentou problemas de hipossegmentação (palavras escritas juntas, sem o devido espaçamento); o aluno 4 também apresentou esse problema, mas conseguiu igualmente produzir um texto. 
No final da intervenção, os avanços foram nítidos e significativos. Os alunos 1 e 2, finalmente, conseguiram produzir textos legíveis. $\mathrm{O}$ primeiro escreveu um texto sem marcação externa do parágrafo (alínea) e em bloco único, porém "com coerência e exposição de mais de uma ideia, que se apresentaram sequenciadas e interligadas entre si" (MORAES, 1999, p. 51). O segundo aluno também teve avanços importantes: conseguiu fazer uso do discurso direto em seu texto, com pontuação apropriada e introduziu estratégias argumentativas. Os alunos 3 e 4 foram os que mais avançaram, porque, na verdade, eram os que já conseguiam produzir textos, mesmo com muitas dificuldades. Esses alunos, ao final do processo, "demonstraram ter se apropriado do significado e do registro do parágrafo" (MORAES, 1999, p. 52). Ambos dividiram seus textos em partes de forma pertinente e com o recuo da margem esquerda, conforme é convencional.

Muitas hesitações, porém, foram frequentes ao longo da intervenção, e a pesquisadora verificou a existência de etapas na evolução das crianças.

Em relação à formatação textual interna do parágrafo, Moraes $(1999$, p. 54) concluiu que as crianças experimentaram algumas hipóteses. Foram elas:

1) inexistência de blocos de ideias, ou seja, o aluno não dividiu o texto em partes;

2) formatação de parágrafos com ideias inconclusas, isto é, o aluno sabia que era preciso fazer a marcação do parágrafo, mas não finalizou a ideia iniciada;

3) tentativas de marcar o parágrafo por meio de quantidades semelhantes de linhas escritas: o aluno estabelece uma quantidade $\mathrm{X}$ de linhas para cada bloco e, independentemente de a ideia ter sido ou não concluída, ele fecha o parágrafo, ao chegar nessa quantidade.

4) agrupamento de ideias associadas num mesmo parágrafo, que seria a marcação aceita pela norma culta.

No tocante à formatação externa, Moraes (1999, p. 54 e 55) pôde perceber que as crianças também diversificaram as formas de marcação. Alguns usos interessantes foram observados, como: 
1) travessão no início de cada linha escrita;

2) ponto final antes de bloco de linhas, cujas apresentações estão numa mesma proporção;

3) travessão antes de cada grupo de linhas escritas, geralmente de extensão semelhante;

4) recuo da margem esquerda apenas na primeira linha, e todo o restante do texto sem esse afastamento.

Como foi visto, à medida que as intervenções ocorriam, os alunos ficavam mais desenvoltos na escrita, estabelecendo uma marcação paragráfica no texto mais próxima da convencionalmente aceita, tanto em nível externo (recuo da margem esquerda) como em nível interno (agrupamento de ideias ou blocos).

Outro estudo que também realizou intervenções foi o de Brande (1999). A pesquisa teve como intuito analisar, antes e após intervenção, a evolução da escrita dos textos de trinta e três crianças da segunda série do ensino fundamental. Foi possível verificar que, no início (diagnóstico inicial), a maioria dos alunos apresentava dificuldades em escrever textos com parágrafo e pontuação adequados. Onze escreveram textos muito confusos ou sem uma lógica na organização das informações. Além disso, foi notada uma repetição excessiva dos conectivos "e" e "daí" e dos pronomes pessoais ele/ela.

No decorrer do ano letivo, a pesquisadora realizou várias atividades com o objetivo de contribuir com o desenvolvimento da escrita das crianças. Após esses momentos, aplicou um diagnóstico final e pôde perceber avanços. Vinte e sete alunos passaram a escrever textos com paragrafação e pontuação adequadas, além de apresentarem coerência e organização.

As pesquisas de Moraes (1999) e Brande (1999), portanto, podem comprovar que é possível alunos das séries iniciais avançarem na questão da paragrafação textual por meio de um trabalho sistemático com os textos. Porém, acreditamos que esse avanço pode ser ainda mais significativo se forem acrescidas a esse trabalho reflexões ainda mais específicas sobre a paragrafação em diferentes gêneros textuais.

A pesquisadora Rocha (1996) realizou um estudo que nos trouxe contribuições importantes para entendermos a relação entre a pontuação e a formatação gráfica do texto. Participaram da pesquisa 115 crianças de $1^{\mathrm{a}}$ a $3^{\mathrm{a}}$ série do ensino fundamental de duas escolas (uma pública 
e uma particular) de Fortaleza - Ceará. Foi solicitado que as crianças recontassem, por escrito, a história de Chapeuzinho Vermelho. Após dois meses da coleta, a pesquisadora realizou também 29 entrevistas com as crianças agrupadas em dupla. Nesses momentos, elas repontuaram dois trechos do diálogo entre o lobo e Chapeuzinho (um apresentado em um único bloco, e o outro, paragrafado).

Antes de apresentarmos os resultados, é preciso salientar que, para a autora, a habilidade de paragrafar está intimamente relacionada à formatação do texto, uma vez que é um dos aspectos relevantes da organização textual.

Segundo Rocha (1996), existe dois tipos de formatação: a externa - "apresentação do texto de forma corrida ou segmentado em blocos de significação (parágrafos), utilizando adequadamente ou não o espaço das linhas do papel" (p. 8) - e a interna - "apresentação, ou não, dos diferentes atos discursivos do texto em sua forma típica de apresentação" (p. 8).

Como principal resultado, a pesquisadora pôde verificar que o domínio da pontuação ocorre paralelamente ao domínio do formato gráfico (interno e externo). Os dados mostraram que as crianças que escreviam textos sem pontuação ou com pouca pontuação também não apresentavam organização gráfico-espacial do texto (ausência de paragrafação). Mais ainda, foi possível perceber que "a formatação do texto tende a seguir uma linha evolutiva, do mesmo modo que a pontuação em geral: ausência quase total de formato gráfico na $1^{\mathrm{a}}$ série, surgimento gradativo na $2^{\mathrm{a}}$ série e consolidação na $3^{\mathrm{a}}$ série" (ROCHA, 1996, p.10).

Ainda foi visto que essa evolução da formatação e da pontuação parece ocorrer de "fora para dentro": o formato global (externo) antecede o formato interno, assim como a pontuação externa antecede a interna. A estudiosa sistematizou essa evolução em quatro níveis:

1) indiferenciação total: no caso das crianças que já utilizavam parágrafos para marcar os episódios da narrativa, mas ainda mantinham o diálogo inserido na narrativa, não conseguindo marcá-los de forma convencional.

2) $1^{\text {a }}$ diferenciação (sem formato gráfico convencional): os diálogos começam a ser diferenciados da narrativa, aparecendo em linhas diferentes, mas ainda sem pontuação adequada. 
3) $2^{\mathrm{a}}$ diferenciação (sem formato gráfico convencional): há um pouco mais de diferenciação dos diálogos. Já aparece pontuação adequada, mas não está consolidada.

4) diferenciação total (com formato gráfico convencional): as formas da narrativa e dos diálogos diferenciam-se plena e sistematicamente.

É possível perceber que as estratégias de pontuação mais evoluídas estavam presentes nos textos das crianças que conseguiam organizar melhor (em partes) as informações.

$\mathrm{Na}$ atividade de repontuar trechos de diálogos, a hipótese inicial da estudiosa era a de que as crianças repontuariam mais facilmente o diálogo que se encontrava paragrafado, pois, visualmente, isso ajudaria a perceber os locais para inserirem a pontuação. No entanto, não foi o que aconteceu com as crianças que inseriram poucos sinais de pontuação em seus textos. Na hora de revisar, elas acrescentaram um pouco mais de sinais no texto não paragrafado, contrariando a hipótese.

Para Rocha (1996, p. 18), esses resultados talvez indiquem que,

para as crianças que se apercebem pouco da pontuação, a organização gráfico-espacial do texto acaba sendo indiferente. Ou talvez, justamente por não atentarem suficientemente para a disposição do texto na página impressa, também pontuem pouco.

Embora tenha havido certo equilíbrio na frequência da pontuação nos dois trechos, é preciso ressaltar que houve outras evidências que podem ratificar a importância dos aspectos gráfico-visuais, como pistas essenciais para a pontuação do texto. Uma das evidências foi o fato de a maioria dos sujeitos ter afirmado ser mais fácil pontuar o texto formatado, em comparação com o texto escrito em bloco único.

A conclusão, segundo Rocha (1996, p.25), é a de que, para pontuar o texto, sobretudo em seus limites externos (final de frase e parágrafos), as crianças apelam para indícios gráfico-visuais e para a disposição espacial do texto. E esse conhecimento funciona não só como fim, mas também como meio para orientar a distribuição da pontuação.

Com base nesse estudo de Rocha, notamos como a aprendizagem da habilidade da paragrafação pode contribuir para outras aprendizagens, 
como a da pontuação, por exemplo, o que a torna fundamental para a formação de um bom escritor.

A pesquisa realizada por Andrade (2010) revela aspectos que merecem ser discutidos, no que se refere ao olhar das crianças para a paragrafação. Ela não tinha a intenção de investigar, especificamente, as capacidades das crianças em dividir seus textos em parágrafos, mas pôde verificar que, na hora da revisão textual, esse aspecto (assim como outros também relacionados aos conhecimentos linguísticos) foi pouco modificado.

A pesquisa em questão buscou conhecer o que os alunos do $4^{\circ}$ ano do ensino fundamental são capazes de revisar quando estimulados a refletir sobre o gênero textual "carta de reclamação", em uma sequência didática, e, assim, verificar o que os estudantes consideram relevante e o que são capazes de fazer no momento da revisão de seus textos.

De forma mais aprofundada, Andrade (2010) investigou quais marcas de revisão textual podem ser encontradas nas cartas de reclamação escritas pelos alunos e se estas se referiam ao conteúdo, à coesão textual, à paragrafação, à pontuação, à ortografia, à caligrafia ou à concordância. Também buscou verificar os tipos de mudanças realizadas durante a revisão dos textos (exclusão, acréscimo, substituição, mudança de posição) e analisar se, no processo de revisão textual, as crianças modificam os textos quanto à dimensão argumentativa.

Participaram da pesquisa professoras e alunos de duas turmas de $1^{\circ}$ ano do $2^{\circ}$ ciclo ( $4^{\circ}$ ano do ensino fundamental) de escolas da Rede Municipal de ensino da cidade do Recife. Para isso, foi solicitado aos alunos produzir uma carta de reclamação para o Prefeito da cidade do Recife, expondo a situação precária dos brinquedos e das praças do bairro em que as escolas estavam situadas. Foram realizadas mais três revisões desse texto, duas individuais e uma em duplas de trabalho.

Foram selecionados 20 alunos, sendo 10 de cada turma. A análise se deu por meio da comparação entre as diferentes versões dos textos dessas crianças.

Os resultados revelaram que a grande maioria das mudanças realizadas nos textos dos alunos dizia respeito ao conteúdo $(54,5 \%)$, sendo o acréscimo o tipo de modificação mais frequente. $\mathrm{O}$ segundo aspecto que mais recebeu atenção nas revisões foi a ortografia, com uma porcentagem de $24,3 \%$ do total das modificações. 
Atrás dos aspectos relacionados a conteúdo e ortografia, vieram as seguintes dimensões textuais: pontuação $(8 \%)$; coesão $(5,8 \%)$; concordância $(4,7 \%)$; paragrafação $(2 \%)$ e caligrafia $(0,7 \%)$, que receberam a atenção das crianças, quando revisaram suas cartas, porém com baixa frequência. Entretanto, o que mais chamou a atenção da pesquisadora foi o fato de essas revisões estarem em função da revisão dos conteúdos.

Segundo Andrade (2010), esses dados contrariam os resultados de outros estudos (GÓES, 1993; FLOWER; HAYES, 1980; SCARDAMALIA; BEREITER, 1992), que defendem que as revisões de textos feitas por crianças ficam circunscritas a questões de ordem ortográfica e/ou alterações superficiais, que não afetam o significado do texto.

A hipótese levantada pela pesquisadora para seus resultados se sustenta no fato de as crianças terem sido estimuladas a refletir sobre a adequação de seu texto à finalidade da interação (reclamar para o prefeito). Ou seja, o tipo de intervenção realizada e o contexto de produção foram fatores decisivos para direcionar o olhar das crianças para outros elementos que vão além da superfície textual.

Como foi possível observar, a paragrafação foi poucas vezes alvo de reescritas, com apenas $2 \%$ dos episódios. Esse dado pode ser reflexo da falta de um ensino mais sistemático dedicado a essa habilidade. Ou ainda reflexo da ênfase dada pela docente nas questões relativas à adequação de seu texto à finalidade da interação, o que pode ter direcionado a atenção dos alunos para essas questões, fazendo-os "esquecer" de outros aspectos. $\mathrm{O}$ fato é que não podemos deixar os alunos sozinhos na tarefa de aprender a paragrafar seus textos. Cabe ao professor promover situações de ensino, bem como orientar a paragrafação nos momentos de escrita.

Em Bessonnat (1988, p. 82), encontramos algumas situações didáticas que seriam potencialmente interessantes para um trabalho reflexivo com a paragrafação, entre as quais destacamos as seguintes: comparação de três versões de um texto paragrafado de formas diferentes, para que os alunos selecionassem a versão que lhe parecessem mais bem organizada; entrega de um texto lacunado, em que faltava um parágrafo, para que os alunos formulassem hipóteses referentes às informações que estariam faltando; recomposição de um texto cujos parágrafos tiveram sua sequência alterada, possibilitando ao professor explorar a relação da segmentação com a articulação lógica do texto. 
É possível perceber que as atividades sugeridas, de fato, contribuem para o desenvolvimento da habilidade de paragrafar. Algumas, por exemplo, vão focar mais os critérios de organização, outras, a articulação interna dos parágrafos. $\mathrm{O}$ que o docente precisa entender, porém, é que somente um tipo de atividade não será suficiente para uma real apropriação da paragrafação pelos alunos. Será necessário que conjugue várias atividades e, assim, realize um trabalho sistemático e reflexivo.

Parece-nos pertinente, ainda, destacar que essas situações de ensino estejam atreladas ao trabalho com os gêneros textuais. Consideramos que, para organizar o texto em partes, o escritor mobiliza estratégias aprendidas por meio do contato com textos diversos. Assim, tende a usar critérios comumente relacionados aos gêneros textuais adotados na situação de escrita. Como sabemos, os textos que circulam socialmente têm certas regularidades que contribuem para que o escritor lance mão das experiências anteriores para a elaboração de novos textos. $\mathrm{Na}$ maior parte das vezes, essas regularidades não implicam regras rígidas; são estratégias comuns à escrita de textos que circulam em uma determinada esfera social para atender a determinadas finalidades.

Por acreditarmos nesse ensino pautado nos gêneros, resolvemos, em nossa pesquisa, focar nas habilidades de escrita das crianças ao escreverem cartas de reclamação. Na próxima seção, abordaremos esse gênero (conceito e movimentos), buscando compreender suas características composicionais e discursivas e assim perceber suas possíveis regularidades.

\section{A argumentação e a carta de reclamação}

De acordo com os estudos realizados por Schneuwly e Dolz (2004), o gênero textual "carta de reclamação" estaria dentro da ordem do argumentar, uma vez que o mesmo apresenta uma predominância de sequências tipológicas argumentativas. Os textos da ordem do argumentar teriam a função primordial de convencer o leitor de algo. São exemplos: as cartas ao leitor, os textos de opinião, as resenhas críticas, as dissertações, entre outros...

No texto predominantemente argumentativo, uma questão primeira emerge: a relevância do ato de argumentar naquela determinada situação. Para que haja a necessidade de argumentar é preciso que exista 
um assunto que dê margens a um debate, proposições que justifiquem e/ou refutem a declaração, enfim, alguém apresentando resistências. Essas características gerais tipificam os textos da ordem do argumentar de uma maneira geral. No entanto, cada gênero tem especificidades, que são historicamente construídas.

Silva e Leal (2007) realizaram uma pesquisa na busca por encontrar elementos característicos do gênero em foco. Para tanto, as pesquisadoras analisaram vinte (20) cartas de reclamação de circulação social. Os resultados encontrados trouxeram informações bastante relevantes e também ajudaram a perceber como comumente é construída sua cadeia argumentativa. Foi possível identificar sete componentes textuais que possivelmente configurariam uma carta de reclamação. São eles: 1) indicação do objeto alvo de reclamação; 2) justificativa para convencimento de que o objeto pode ser (merece ser) alvo de reclamação 3 ) indicação de sugestões de providências a serem tomadas; 4) justificativa para convencimento de que a sugestão é adequada; 5) Indicação das causas do objeto alvo da reclamação; 6) Contra-argumentação relativa ao objeto alvo de reclamação; 7) Contra-argumentação relativa às sugestões.

Nas cartas de circulação analisadas, os componentes 1 (indicação do objeto alvo de reclamação) e 2 (justificativa da reclamação) foram os que apareceram em todas as cartas. Dessa forma, para reconhecermos que uma carta é uma "carta de reclamação" parece ser primordial observarmos se ela traz a indicação de objeto(s) alvo(s) da reclamação e o movimento de justificação da relevância de tal indicação.

Em seguida, foi encontrado um amplo uso do componente 3, a indicação de sugestões tendo em vista a resolução do problema, que teve doze aparições (60\%). Esse componente estava muito presente nos textos analisados, constituindo uma estratégia para mostrar ao destinatário a queixa de que era possível resolver o problema descrito.

O movimento de justificar a(s) sugestão(ões) dada(s), na tentativa de convencer o leitor da sua adequação e pertinência (componente 4), também foi utilizado em várias cartas (em 8 das 20 cartas - 40\%). Do mesmo modo, foi encontrada em oito cartas a tentativa de citar e explicar as possíveis causas da ocorrência do problema em foco. (componente 5).

Outros movimentos, no entanto, tiveram baixa incidência. Foi o caso da contra-argumentação relativa ao objeto alvo de reclamação (componente 6) e da contra-argumentação relativa às sugestões (componente 7); ambas tiveram apenas três aparições (15\%). As 
pesquisadoras ressaltam, porém, que essa baixa incidência não pode ser interpretada como indício de que tais componentes são irrelevantes. Eles são fundamentais em situações em que as partes envolvidas já estejam em processo de negociação e não haja um consenso sobre quem é o culpado. As análises das cartas de circulação social mostraram, portanto, que quanto maior for o uso desses diversos componentes, maiores são as chances de o texto ter uma cadeia argumentativa apropriada para as finalidades previstas.

\section{Metodologia}

Participaram da pesquisa alunos de cinco turmas (duas turmas do $3^{\circ}$ ano, uma do $5^{\circ}$ ano e duas do $7^{\circ}$ ano) que estudavam na Rede Pública de Ensino de Pernambuco. Os alunos vivenciaram uma mesma sequência didática relacionada ao gênero "carta de reclamação", com o intuito de contribuir para que eles pudessem ativar seus conhecimentos prévios e construir representações/conhecimentos sobre esse gênero. Com a intervenção, procuramos apenas diminuir os efeitos do possível "desconhecimento" do gênero, facilitando a produção da carta e não "bloqueando" uma possível organização dos textos em partes. Essas sequências foram mediadas pelas docentes regentes da turma, sem intervenções das pesquisadoras durante a vivência.

No final da sequência, coletamos 151 cartas elaboradas pelos alunos. Para essa pesquisa, analisamos 37 textos. Excluímos da amostra todos os textos produzidos por alunos que apresentavam distorções idade/ ano, textos escritos de forma não convencional (ilegíveis) e os que não produziram o gênero solicitado (carta de reclamação). Mesmo adotando esses critérios, tivemos um número maior de textos, então, realizamos um sorteio.

Para responder a nossa questão de pesquisa, ou seja, "como a paragrafação e a argumentação se realizam em diferentes etapas do ensino fundamental", analisamos as estratégias de organização dos textos em partes, na intenção de verificar quais foram pertinentes. Depois, mapeamos o desenvolvimento da cadeia argumentativa, ou seja, o uso dos componentes textuais próprios ao gênero "carta de reclamação". De posse dos dados, agrupamos os textos pela relação entre a paragrafação (adequada ou insuficiente) e a argumentação (consistente ou com fraca consistência). 
Consideramos como boa paragrafação dois casos: quando os textos eram escritos em bloco único e realmente não precisavam ser paragrafados, por trazerem poucas informações e serem mais concisos; ou quando os textos eram divididos em parágrafos, e cada um destes trazia um objeto alvo de reclamação, seguido de argumentação, ou quando cada parágrafo trazia um elemento dessa argumentação desenvolvido.

Já a paragrafação insuficiente era aquela em que o texto apresentava um grande número de informações agrupadas em bloco único ou em um mesmo parágrafo, sendo necessário outra organização textual para que o texto ficasse mais claro para o leitor.

Em relação à argumentação, verificamos se a cadeia argumentativa foi desenvolvida, de forma que o texto trouxesse uma justificativa em relação à relevância da reclamação feita, assim como um movimento de contra-argumentação. Na ausência desses elementos, consideramos o texto com fraca consistência argumentativa.

Na seção 4 (itens 1 a 4), apresentaremos detalharemos essa categorização, exemplificando por meio do movimento de escrita dos textos o que foi considerado uma paragrafação boa ou insuficiente e uma argumentação consistente ou com fraca consistência.

\section{Resultados e discussão}

\subsection{Uma categorização para os textos produzidos: as estratégias de paragrafação adotadas pelas crianças e suas relações com a cadeia argumentativa}

Após análise dos textos quanto à paragrafação e à argumentação, chegamos a quatro categorias: cartas com boa paragrafação e consistência argumentativa; cartas com boa paragrafação, mas com lacunas na consistência argumentativa; cartas com paragrafação insuficiente e boa consistência argumentativa; cartas com paragrafação insuficiente e fraca consistência argumentativa. A seguir, apresentaremos cada um desses agrupamentos. 


\subsubsection{Cartas com estratégias de paragrafação adequadas ao texto e boa consistência argumentativa}

Encontramos cartas de reclamação cuja paragrafação e argumentação foram bem desenvolvidas. Contabilizamos os casos e vimos que $18,9 \%$ do total de cartas de reclamação pertencem a esse grupo. Não é um número alto, mas indica que há alunos que conseguem articular a habilidade de paragrafar e argumentar em seus escritos. Inserimos neste grupo os seguintes casos descritos:

- textos escritos em bloco único com apresentação de um único objeto de reclamação acompanhado de vários componentes textuais (justificativa do objeto alvo de reclamação e/ou sugestões e/ou, justificativas das sugestões e/ou contraargumentação);

- textos com parágrafos, com apresentação de um objeto de reclamação, acompanhado de cadeia argumentativa: cada parágrafo é um componente argumentativo (justificativa do objeto de reclamação, sugestões, justificativa das sugestões, contra-argumentação);

- textos com parágrafos, com apresentação de vários objetos de reclamação, acompanhados de cadeia argumentativa: cada parágrafo é um componente argumentativo (justificativa do objeto de reclamação, sugestões, justificativa das sugestões, contra-argumentação);

- textos com parágrafos, com apresentação de vários objetos de reclamação, acompanhados de cadeia argumentativa: cada parágrafo é uma reclamação diferente, acompanhada de argumentação referente à reclamação alvo do parágrafo.

Para ilustrar, selecionamos uma das cartas pertencentes a essa categoria: 
340

Revista de Estudos da Linguagem, Belo Horizonte, v. 26, n. 1, p. 321-353, 2018

Efp, aluna do

, queria the

informar; que onă và en ceamo ctrdars ar aluunas dersta ieccala queríamess quie o ronker nos atorderere cam ateregaro.

par que chaveomos epor uma certa dificuldods unuito groonde um ir as ctranheiro devera evcala; cprociramas de mais chigiene, deais o mal cheiro l'a direcerganizacão ú vintuppertáriel.

par exumplo: (O drankeiro das deraleververes ú limpar, cheirovo, una evâmica; of par que o nosto onowe crevid ver?

(-) venhar apode at punzoor que as alunas que

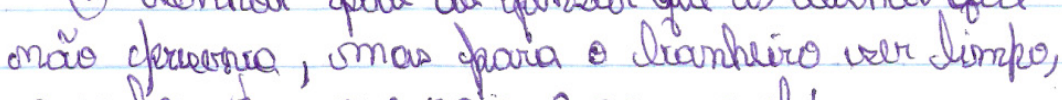
- comhar ciem que agur cam moral !

Tanokém tondo cesso epartunidade de omiom

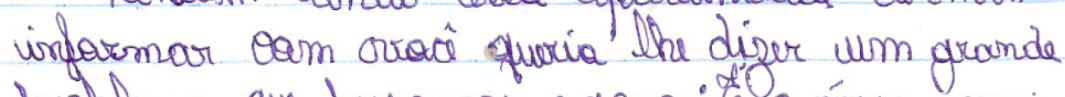

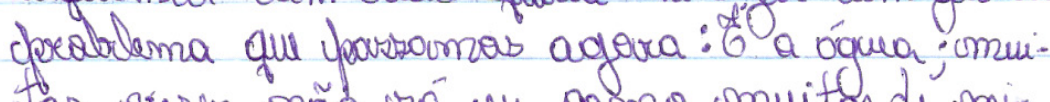
tas arezes onãos vó un darno omvito de mimas amigas, elegarmas um cara y ficaumas

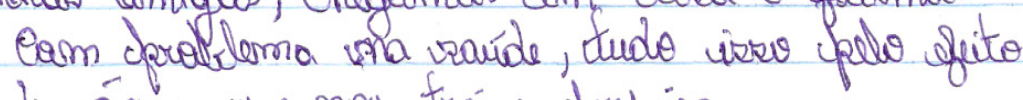
da água que mors ctráso perefuiso.

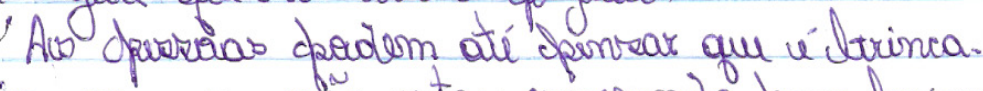
deira somas en uncio estan escrerwendo apara derincor, u rim cleova healar veório. 
Eu, aluna do , queria lhe informar; que não só eu como todos os alunos dessa escola queríamos que o senhor nos atendesse com atenção.

Por que passamos por certa dificuldade muito grande em ir ao banheiro dessa escola; precisamos de mais higiene, pois o mal cheiro e a desorganização é insurpotável.

Por exemplo: O banheiro dos professores é linpo, cheiroso, na cerâmica; E por que o nosso não pode ser?

O senhor pode até pensar que os alunos que não preserva, mas para o banheiro ser limpo, o senhor tem que agir com moral!

Também tendo essa oportunidade de mim informar com você queria lhe dizer um grande problema que passamos agora: É a água; muitas vezes não só eu como muitas de minhas amigas, chegamos em casa e ficamos com problema na saúde, tudo isso pelo efeito da água que nos trás o prejuízo.

As pessoas podem até pensar que é brincadeira, mas eu não estou escrevendo para brincar, e sim para falar sério.

$7^{\circ}$ ano, sexo feminino, 12 anos.

O texto acima foi classificado como pertencente ao tipo "textos com parágrafos, com apresentação de vários objetos de reclamação”, acompanhados de cadeia argumentativa. Notamos que a criança reclama de mais de um problema na escola (a má situação do banheiro e a falta de água potável para beber).

Cada parágrafo ela dedica a apresentar um componente textual, dividindo sua reclamação em vários blocos. No primeiro parágrafo do texto, ela faz uma introdução; no segundo, apresenta o que seria o primeiro problema. Em seguida, no terceiro parágrafo, traz uma justificativa para convencer o responsável a consertar os banheiros (professores e alunos têm o mesmo direito). No quarto parágrafo, a aluna parece reproduzir uma possível fala do diretor da escola contra a sua reclamação, na qual contestaria a reclamação afirmando que não há por que investir no conserto dos banheiros se são os próprios alunos que não preservam. Em seguida, ela refuta essa ideia dizendo que se os alunos não preservam é porque ele (o diretor) não age com moral. No quinto parágrafo, há a apresentação do segundo objeto alvo de reclamação e, por fim, no último parágrafo, realiza-se o fechamento do texto, buscando sensibilizar o leitor para a seriedade da carta. 
Embora o texto apresente problemas na escolha dos recursos coesivos para iniciar e retomar os parágrafos, o que daria uma maior unidade ao texto, pode-se dizer que a carta cumpriu com sua finalidade de escrita.

Assim como a aluna citada, outros estudantes também evidenciaram ter estratégias eficientes para organizar a cadeia argumentativa, segmentando o texto de modo a auxiliar o leitor a entendê-la. As crianças autoras dessas cartas conseguiram escolher acertadamente a melhor forma de dividir o seu texto. Se a carta trazia apenas um objeto, preferiram desenvolvê-lo em um único parágrafo ou, então, dividir os componentes que formavam a cadeia entre os blocos, de modo que cada qual ficasse em um parágrafo diferente. Se na carta estavam sendo explicitados vários objetos de reclamação, os sujeitos, então, relacionavam os objetos aos blocos (cada parte tratava de uma reclamação) ou então agrupavam os componentes por parágrafo (exemplo: todas as justificativas dos objetos apresentados ficavam em um só bloco).

Todas essas estratégias colaboram com o leitor, e, de fato, esses textos podem ser considerados bem paragrafados.

\subsubsection{Cartas com estratégias de paragrafação adequadas ao texto, mas com lacunas na consistência argumentativa}

Nessa categoria estão presentes os textos cuja divisão colaborou com o trabalho do leitor. Trata-se de textos bem paragrafados, mas que apresentam lacunas na argumentação, seja por não desenvolver os objetos de reclamação apresentados, seja por desenvolver apenas alguns deles. De todas as cartas de reclamação analisadas, 37,8\% foram entendidas como pertencentes a este segundo grupo. Eis os casos:

- textos com parágrafos, com apresentação de vários objetos de reclamação, sem cadeia argumentativa: cada parágrafo é uma reclamação diferente, sem justificativas.

- textos com parágrafos, com apresentação de vários objetos de reclamação, alguns dos quais acompanhados de cadeia argumentativa: cada parágrafo é uma reclamação diferente, acompanhada ou não de justificativa referente à reclamação alvo do parágrafo; 
- bloco único em textos com apresentação de vários objetos de reclamação, sem outros componentes textuais (só apresentação das reclamações sem argumentação relativa a elas).

Nesses casos, novamente julgamos que a paragrafação foi adequada ao texto construído. Por exemplo, na escrita do texto em bloco único, as crianças não desenvolveram a cadeia argumentativa, e, por isso, seus textos não precisavam ser divididos em parágrafos. Se assim fosse, as cartas ficariam muito fragmentadas, e os parágrafos iriam parecer mais tópicos do que um encadeamento de ideias.

Nos demais casos incluídos nesse grupo de cartas, as crianças relacionavam cada parágrafo a uma reclamação. Essa estratégia permite ao leitor visualizar bem quais são os problemas vivenciados. No entanto, tais reclamações - ou pelo menos parte delas - não foram desenvolvidas. Para ilustrar, selecionamos umas das cartas pertencentes a essa categoria:

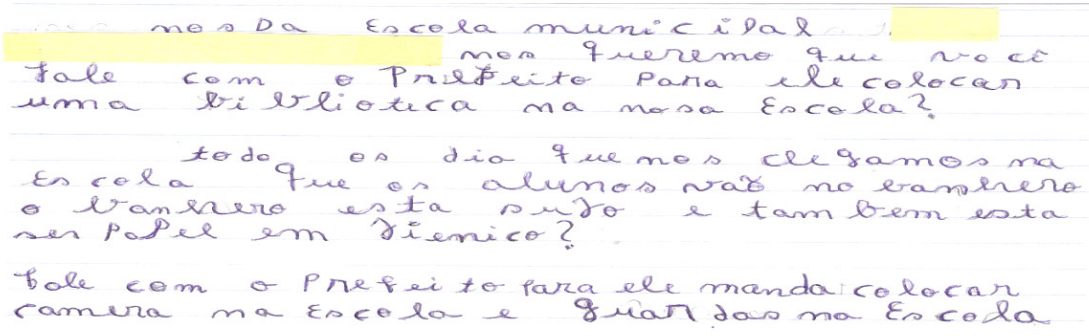

nós da escola municipal nos queremo que você fale com o prefeito para ele colocar uma biblioteca na nossa escola?

todo os dia que nos chegamos na Escola que os alunos vão no banheiro o banheiro esta sujo e também esta sem papel jienico? fale com o prefeito para ele manda colocar câmera na Escola e guardas na Escola

$3^{\circ}$ ano, sexo masculino, 8 anos.

A carta foi organizada em três paragrafados. A estratégia utilizada foi a de apresentar um objeto alvo de reclamação por bloco. No primeiro, a reclamação é referente à falta de biblioteca na escola; no segundo, o aluno 
relata o problema da sujeira no banheiro; e, no terceiro, ele usa o pedido como forma de denunciar a falta de segurança na escola. Consideramos que essa divisão do texto favorece a compreensão leitora. Contudo, o aluno não dedicou esforços para convencer os responsáveis a solucionar os problemas. Por que esses problemas estão afetando os alunos? Por que devem ser resolvidos?

A tarefa de argumentar não é fácil. O locutor, para produzir o sentido que pretende, precisa refletir sobre o que seus possíveis interlocutores podem pensar a respeito do texto. A presença do "outro" o fará perceber que apenas expor seu ponto de vista já não é suficiente. É necessário ainda justificá-lo e até expor contra-argumentos, para evitar seu enfraquecimento. Os alunos que escreveram cartas categorizadas como pertencentes a esse grupo 2 demonstraram bem essas dificuldades. Cerca de um terço dos alunos conseguiu sinalizar os problemas que afetavam as escolas, mas os textos careciam de aprofundamento por falta de argumentos que justificassem a relevância de sua reclamação e convencesse o responsável pelo problema da necessidade de resolução deste.

Dominar as estratégias argumentativas não acontece ao natural, espontaneamente. Por isso, é necessário um trabalho sistemático com textos dessa ordem na escola, tal como é o caso da carta de reclamação. No entanto, Leal (2003) constatou que os textos argumentativos aparecem com pouca frequência na sala de aula e, quando são objetos de ensino, raramente são exploradas as estratégias argumentativas, tão importantes para a compreensão e a produção dos textos dessa ordem.

Atividades como ler um artigo de opinião e destacar os argumentos do autor, realizar um debate oral em sala de aula sobre tema controverso, após momentos de estudo sobre o tema e levantamento de argumentos e contra-argumentos para lançar no debate, são exemplos de situações didáticas que favorecem o desenvolvimento da habilidade de argumentar dos alunos.

\subsubsection{Cartas com paragrafação insuficiente, mas com boa consistência argumentativa}

$\mathrm{Na}$ terceira categoria, estão os textos nos quais, ao contrário dos dois outros apresentados, a estratégia de organização dos parágrafos não foi bem sucedida ou então não são possíveis de ser percebidas.. As crianças, autoras dos textos aqui agrupados, mesmo sem paragrafarem 
bem, conseguiram desenvolver de forma consistente a argumentação, defendendo a relevância de suas reclamações. Identificamos que 27\% das cartas pertencem a essa categoria. Eis os casos:

- bloco único em textos com apresentação de vários objetos de reclamação acompanhados de vários componentes textuais relativos a cada uma das reclamações (justificativa do objeto de reclamação e/ou sugestões e/ou justificativas das sugestões e/ contra-argumentação);

- Cartas em que aparentemente não há uma divisão lógica dos blocos (textos com parágrafos), mas apresentam uma boa consistência argumentativa. A seguir apresenta-se um exemplo:

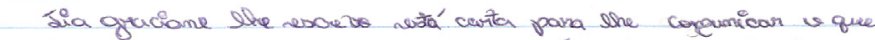

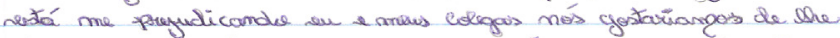

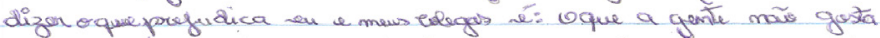

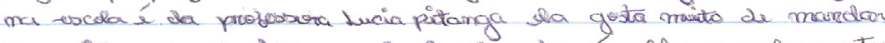

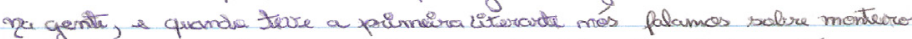

hobato foi a quarta da mantra coma da Tarde ela bó fozia tirar

foto dos aburos dula inviros de ela mandar alures dela ayudar

a gente a explica equem explicar Judo fó foi os oblunos da tarde e

monhurn dos alumos dela a yudou e ainda más quando as máe lang

ver en e mous colegas afpurosentado ela tíra as má e monndaria

elas ver fantochis que exa da sala dela lis vintiladows menz

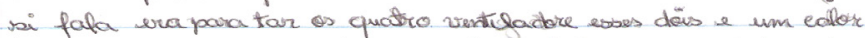

danado ninguem superta. a quadra etá mau cimentada e tern

mintas pedras e vidros e sem fotar quando a gente $v a i$ brincar

lár má̃ puta nä́ sá faz a gente machucar e tambrém túnha

que aumentar a muiro da quadra. E o campinho de aréa tem que

potar mais aréia trrar o pote e cumentaro muro. E a horta que sta

counda os pedacos etem que botara serca, o quesur quero que facia

na excolatamboem inouido aqui meste texto. quero tamkém que almente

- salario das professora petar puros e cadeixas mais confortaves,

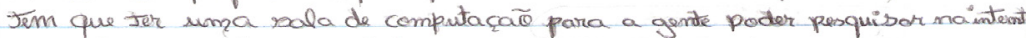
má̃ goto dors briggus \& a falta de sespeito com as professora e

fuci onacios. Cumertar a biblieteca betar mais liveros. Fer mais se guranca

na escola ná deixar a turma da manka rasgar nos cartases e

traluahos sambém a falta de eaderno, Lapis, borracha, cola, bapis de pau para pintor, lapis de sercy, a nossou porta que ersta com a fechaduria

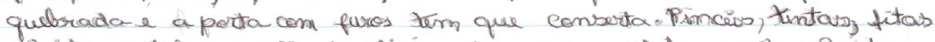

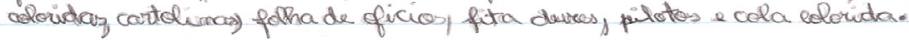


Tia lhe escrevo está carta para lhe comunicar o que está prejudicando eu e meus colegas nós gostaríamos de lhe dizer o que prejudica eu e meus colegas é: o que a gente não gosta na escola é da professora Lúcia ela gosta muito de mandar na gente, e quando teve a primeira literarte nós falamos sobre monteiro Lobato foi a quarta da manhã com a da tarde ela só fazia tirar foto dos alunos dela invés de ela mandar os alunos dela ajudar a gente a explica quem explicou tudo só foi os alunos da tarde e nenhum dos alunos dela ajudou e ainda mais quando as mães iam ver eu e meus colegas apresentando ela tira as mães e mandava elas ver fantoches que era da sala dela Os ventiladores nem si fala era para tar os quatro ventilador esses dois e um calor danado ninguém suporta. A quadra está mau cimentada e tem muitas pedras e vidros e sem falar quando a gente vai brincar lár não presta não só faz a gente se machucar e também tinha que aumentar o muro da quadra. E o campinho de aréa tem que potar mais aréia tirar o pote e aumentar o muro. E a horta que esta caindo os pedaços e tem que botar serca, o que eu quero que faça na escola também incruindo aqui nesse texto. Quero também que almente o salario das professora e potar piros e cadeiras mais confortaves, tem que ter uma sala de computação para que a gente poder pesquisar na internet não gosto das brigas e a falta de respeito com as professora e fucionarios. Aumentar a biblioteca e botar mais livros. Ter mais segurança na escola. Não deixar a turma da manhã rasgar nos cartazes e trabalhos. Também a falta de caderno, lápis, borracha, cola, lápis de pau para pintar, lapis de sera, a nossa porta que esta com a fechadura quebrada e a porta com furos tem que conserta. Pinceis, tintas, fitas coloridas, cartolinas, folha de ofícios, fita dures, pilotos e cola colorida.

$5^{\circ}$ ano, sexo feminino, 11 anos.

Como vemos, o texto foi escrito em bloco único com vários objetos de reclamação explicitados. A sobrecarga de informações é grande. A melhor estratégia, nesse caso, seria relacionar os blocos aos objetos de reclamação, ou seja, apresentar cada reclamação em um parágrafo. Isso contribuiria com a leitura e entendimento das questões expostas. Outras crianças tiveram o mesmo tipo de produção.

Também classificamos nessa categoria as cartas nas quais não foi possível perceber os critérios adotados para dividir os blocos: 
nem separavam cada reclamação em um parágrafo nem separavam os componentes textuais próprios do gênero solicitado, mas tinham cadeias consistentes relacionadas a essas reclamações.

Ao lermos as cartas do primeiro grupo, foi possível perceber o quanto algumas crianças e alguns adolescentes se esforçaram para dar uma lógica coerente à organização de seus escritos. Eles pareciam reconhecer que a divisão do texto em partes não podia ser aleatória, ao livre arbítrio do escritor. No entanto, no caso das cartas agrupadas nesse terceiro grupo, não parecia haver uma lógica clara para a organização do texto em partes, ou seja, não foi possível identificar quais foram os possíveis critérios utilizados na paragrafação. Além disso, outras crianças tinham claramente uma estratégia argumentativa bem articulada, mas optavam por segmentações nem sempre úteis aos seus propósitos, ou seja, poderiam aprimorar suas próprias estratégias. É o caso da carta utilizada como exemplo acima.

\subsubsection{Cartas com paragrafação insuficiente e fraca consistência argumentativa}

No último agrupamento, classificamos todas as cartas cujos autores não escolheram uma paragrafação adequada ao texto construído. Nelas, também se viam argumentações pouco consistentes. Os objetos eram apresentados sem desenvolvimento da argumentação. Algumas vezes chegavam apenas a acrescentar sugestões. Cerca de $16 \%$ das cartas de reclamação foram categorizadas como pertencentes a esse grupo.

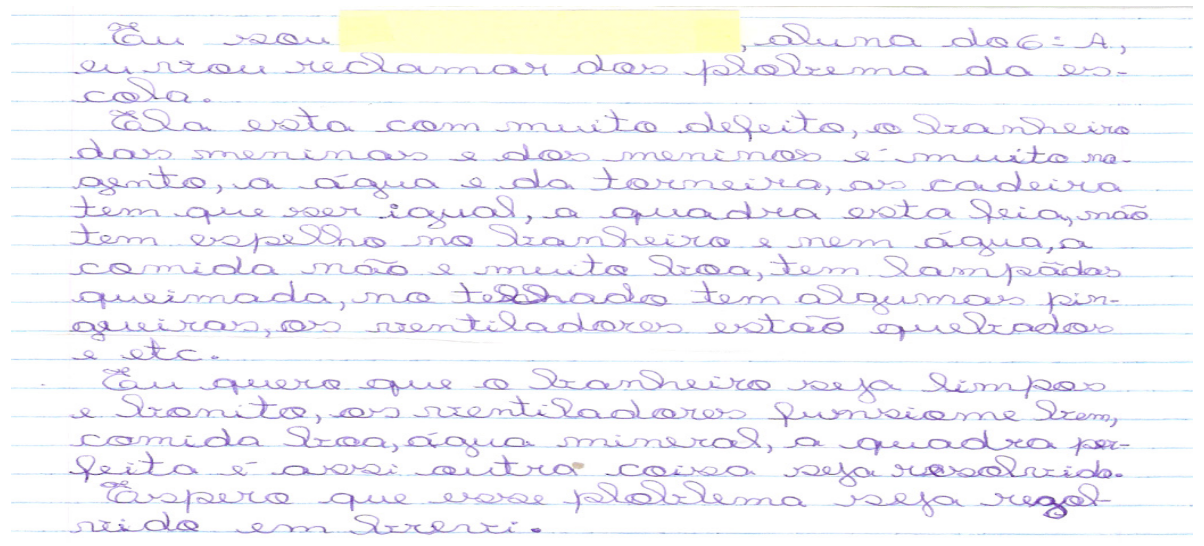


Eu sou , aluna do $6^{\circ} \mathrm{A}$, eu vou reclamar dos ploblemas da escola.

Ela esta com muito defeito, o banheiro das meninas e dos meninos é muito nojento, a água e da torneira, as cadeira tem que ser igual, a quadra esta feia, não tem espelho no banheiro e ne água, a comida não é muito boa, tem lampâdas queimada, no telhado tem algumas pingueiras, os ventiladores estão quebados e etc.

$\mathrm{Eu}$ quero que o banheiro seja limpos e bonito, os ventiladores funsione bem, comida boa, água mineral, a quadra perfeita é assi outra coisa seja resolvido.

Espero que esse ploblema seja rezolvido em brevi.

$7^{\circ}$ ano, sexo feminino, 14 anos.

A aluna deixa claro quais os problemas denunciados, contudo não aprofunda suas reclamações, ou seja, não as justifica nem contraargumenta a seu favor. Depois de elencar os problemas, passa a dar sugestões de possíveis soluções (exemplo: a água deveria ser mineral). Em relação à paragrafação, não foi possível identificar uma estratégia lógica na organização. Os parágrafos não foram construídos para separar nem os objetos alvo de reclamação nem os componentes textuais.

\subsection{Comparando os textos escritos por crianças de diferentes anos de escolaridade}

Definidas essas quatro categorias que sistematizam, de forma mais evidente a relação entre a paragrafação e a construção da cadeia argumentativa, partimos para entender como se processa tal relação entre o nível de escolaridade e as turmas. Nossa intenção foi verificar se havia diferenças entre as turmas de diferentes anos de escolaridade e entre as turmas do mesmo ano, no que se refere à presença em uma ou outra categoria. Contabilizamos primeiro os dados por ano de escolaridade, conforme tabela 1 a seguir. 
TABELA 1 - Relação entre a paragrafação (adequada ou insuficiente) e a argumentação (consistente ou com fraca consistência) por ano de escolaridade

\begin{tabular}{c|c|c|c|c|c|c}
\hline \multirow{2}{*}{ Categorias } & \multicolumn{2}{|c|}{$3^{\circ}$ ano } & \multicolumn{2}{c|}{$5^{\circ}$ ano } & \multicolumn{2}{c}{$7^{\circ}$ ano } \\
\cline { 2 - 7 } & Freq. & $(\%)$ & Freq. & $(\%)$ & Freq. & $(\%)$ \\
\hline $\begin{array}{c}\text { 1) Cartas com paragrafação } \\
\text { adequada e boa consistência } \\
\text { argumentativa }\end{array}$ & 3 & 27,2 & 2 & 20 & 2 & 12,5 \\
\hline $\begin{array}{c}\text { 2) Cartas com paragrafação } \\
\text { adequada, mas com fraca } \\
\text { consistência argumentativa }\end{array}$ & 5 & 45,4 & 4 & 40 & 5 & 31,2 \\
\hline $\begin{array}{c}\text { 3) Cartas com paragrafação } \\
\text { insuficiente e boa } \\
\text { consistência argumentativa }\end{array}$ & 1 & 9,09 & 4 & 40 & 5 & 31,2 \\
\hline $\begin{array}{c}\text { 4) Cartas com paragrafação } \\
\text { insuficiente e fraca } \\
\text { consistência argumentativa }\end{array}$ & 2 & 18,1 & - & - & 4 & 25 \\
\hline Total & 11 & 99,8 & 10 & 100 & 16 & 99,9 \\
\hline
\end{tabular}

Fonte: Elaborada pelas autoras.

Observando os números, nota-se que as turmas do $3^{\circ}$ ano obtiveram índices melhores do que turmas do $5^{\circ}$ e $7^{\circ}$ anos. Ou seja, alunos com menor tempo de escolaridade se saíram melhor do que os de anos mais avançados. No entanto, ao observar melhor os dados por turma verificamos que o melhor desempenho ocorreu, especificamente, em uma das turmas do $3^{\circ}$ ano e não em ambas. Por exemplo, enquanto todas as cartas de reclamação dos alunos da turma 1 foram escritas em bloco único, na turma 2, a grande maioria organizou seu texto em dois ou mais parágrafos.

São duas realidades distintas que nos fazem crer na possibilidade de turmas do $3^{\circ}$ ano conseguirem dividir seus textos de forma semelhante à turmas de anos mais avançados, como também foi constatado no estudo de Moraes (1999).

Os dados da tabela 2 ratificam essa diferença entre as turmas. 
TABELA 2 - Quantidade de textos por turma com paragrafação adequada e argumentação consistente

\begin{tabular}{l|c|c|c|c|c}
\hline \multirow{2}{*}{ Categorias } & \multicolumn{2}{|c|}{$3^{\circ}$ ano } & $5^{\circ}$ ano & \multicolumn{2}{c}{$7^{\circ}$ ano } \\
\cline { 2 - 6 } & Turma 1 & Turma 2 & Turma 4 & Turma 5 & Turma 6 \\
\cline { 2 - 6 } & $(\%)$ & $(\%)$ & $(\%)$ & $(\%)$ & $(\%)$ \\
\hline $\begin{array}{l}\text { Cartas com paragrafação } \\
\text { adequada e consistência } \\
\text { argumentativa }\end{array}$ & 20,0 & 33,3 & 20,0 & 9,09 & 20,0 \\
\hline
\end{tabular}

Fonte: Elaborada pelas autoras.

Como vemos, ao compararmos os dados das turmas de diferentes anos, de forma separada, constatamos que uma turma do $7^{\circ}$ ano (turma 5) demonstrou apresentar mais dificuldades para paragrafar e argumentar do que uma turma do $3^{\circ}$ ano.

Uma hipótese levantada para esse resultado é a possível influência do tipo de trabalho pedagógico desenvolvido com esses alunos ao longo do $3^{\circ}$ ano, ou mesmo dos anos antecedentes, relativo à consistência das atividades propostas dentro da sequência didática sobre o gênero carta de reclamação. Além disso, observações informais realizadas mostraram que a docente da turma parecia desenvolver um trabalho bastante sistemático com leitura e produção textual. Acreditamos que em suas aulas eram criados diversos momentos de contato com textos e, possivelmente, reflexões sobre os gêneros textuais e/ou organização textual, o que, de fato, colaboraria para um maior desenvolvimento dos alunos.

Nas turmas do $7^{\circ}$ ano, entretanto, as aulas em que a sequência didática foi desenvolvida se deram de forma mais aligeirada, pois as professoras das turmas só dispunham de uma hora e meia de aula, em razão de o horário ser dividido com outras disciplinas. Notamos também que vários aspectos relativos ao gênero estudado foram pouco explorados, tais como as reflexões sobre as características sociodiscursivas da carta de reclamação. 


\section{Considerações finais}

Acreditamos que a primeira contribuição da pesquisa está na própria abordagem do tema, uma vez que esse assunto, como pudemos acompanhar ao longo do referencial teórico, é pouco discutido entre os estudiosos da área. Com base nesse trabalho, aprofundamos o estudo sobre a paragrafação e compreendemos melhor, por exemplo, a relação entre a construção de parágrafos e os gêneros textuais, em particular o gênero carta de reclamação.

É preciso reconhecer, no entanto, que não é possível identificar, com clareza, as especificidades em relação à organização dos parágrafos em todos os gêneros. Há gêneros que são mais fluidos e variam mais em relação à sua organização, de modo que é difícil estabelecer especificidades em relação à construção dos parágrafos.

No caso da carta de reclamação, pudemos verificar que as principais estratégias de paragrafação constituíram-se de formas diferentes de se escrever esse gênero textual: 1) com um parágrafo de abertura e/ou fechamento e um parágrafo contendo toda a reclamação; 2) com parágrafos relacionados aos componentes textuais (objeto alvo de reclamação, justificativa, sugestão para resolver o problema, indicação de possíveis causas, entre outros) 3) relacionadas aos objetos alvo da reclamação; 4) com parágrafos ora relacionados aos objetos de reclamação ora aos componentes textuais.

Os resultados mostraram ainda que alunos dos anos iniciais do ensino fundamental já são capazes de construir parágrafos e atribuir um sentido lógico a essa divisão. Em relação à argumentação, muitos conseguem produzir justificativas e alguns até chegam à contra- argumentar.

Mesmo havendo alguns alunos que já demonstravam certa desenvoltura nessas habilidades, constatamos que havia casos de alunos que, apesar de paragrafarem de maneira adequada, não conseguiam desenvolver bem sua argumentação.

Vemos, portanto, que as estratégias para satisfazer as condições do contexto de produção e organizar o texto, de maneira a ajudar o leitor na compreensão, não é algo adquirido espontaneamente, mas construído por meio da mediação de escritores mais experientes, como o professor. Por isso mesmo, os nossos alunos precisam de mediadores nessa tarefa de se apropriar da paragrafação, pois, enquanto alguns, mais observadores, constroem suas hipóteses, outros passam mais tempo vivendo a angústia de não entenderem as razões para terem de fazer tal divisão. 
É necessário definir boas estratégias didáticas para ensinar as crianças a paragrafar os textos. Contudo, reconhecemos que o professor dispõe de poucos materiais que o orientem na condução desse ensino. Esse talvez seja um dos aspectos que pode gerar um trabalho assistemático com a paragrafação. Também há escassez de momentos de reflexão sobre o tema em sala de aula.

Os resultados de nossa pesquisa reforçam o fato de que mesmo demonstrando possuir tais conhecimentos, seja de forma intuitiva ou não, a escola precisa garantir um espaço pedagógico para ajudar os alunos a avançarem em seus conhecimentos e superarem suas dificuldades.

\section{Referências}

ABARCA, E. V.; RICO, G. M. Por que textos são tão difíceis de compreender? As inferências são a resposta. In: TEBEROSKY, A.; OLLER, C. et al. Compreensão de leitura: a língua como procedimento. Porto Alegre: ArtMed, 2002.

ABARCA, E. V.; RICO, G. M. Por que textos são tão difíceis de compreender? As inferências são a resposta. In: TEBEROSKY, A; OLLER, C. et al. Compreensão de leitura - A língua como procedimento. Porto Alegre: ArtMed, 2002.

ANDRADE, R. M. B. L. de. Revisão de cartas de reclamação: reflexões sobre as modificações realizadas por crianças. 2010. 267f. Dissertação (Mestrado em Educação) - Programa de Pós-Graduação em Educação, Universidade Federal de Pernambuco, Recife, 2010.

BAKHTIN, M. Marxismo e filosofia da linguagem. 2. ed. São Paulo: Hucitec, 2002.

BESSONNAT, D. Le Découpage em paragraphes et ses fonctions. Pratiques, Cresef, n. 57, p. 81-105, Mars 1988.

BRANDE, C. A. Produção de textos na escola: aprendendo a ensinar. In: CONGRESSO DE LEITURA - COLE, 12., 1999, Campinas. Anais... Campinas: Unicamp, 1999.

FLOWER, L.; HAYES, J. A cognitive process theory of writing. In: RUDDDELL, R.; RUDDELL, M.; SINGER, H. (Ed.). Theoretical models and processes of reading. Newark: I. R. A, 1980. p. 928-950. 
GARCIA, O. M. Comunicação em prosa moderna: aprenda a escrever, aprendendo a pensar. 2. ed. Rio de Janeiro: Fundação Getúlio Vargas, 1997.

GÓES, M. C. R. A criança e a escrita: Explorando a dimensão reflexiva do ato de escrever. In: SMOLKA, A. L. B.; GÓES, M. C. R. (Org.). A linguagem e o outro no espaço escolar: Vygotsky e a construção do conhecimento. Campinas: Papirus, 1993.

KATO, M. A. O aprendizado da Leitura. 4. ed. São Paulo: Martins Fontes, 1995.

LEAL, T. F. Produção de textos na escola: a argumentação em textos escritos por crianças. 2003. Tese (Doutorado em Educação) - PósGraduação em Psicologia Cognitiva, Universidade Federal de Pernambuco, Recife, 2003.

MORAES, M. J. F. Características da paragrafação na escrita infantil. 1999. Monografia (Graduação) - Universidade Federal de Pernambuco, Recife, 1999.

ROCHA, I. L. V. Pontuação e formato gráfico do texto: aquisições paralelas. Revista DELTA, PUC-SP, v. 12, n. 1, p. 1-34, 1996.

SCARDAMALIA, M.; BEREITER, C. Dos modelos explicativos de los procesos de composición escrita. Infancia y aprendizaje, Taylor \& Francis Online, n. 58, p. 43-64, 1992.

SCHNEUWLY, B.; DOLZ. J. Gêneros orais e escritos na escola. Campinas: Mercado das Letras, 2004.

SCHNEUWLY, B. Le language écrit chez l'enfant: La production des textes informatifs et argumentatifs. Neuchâtel: Delachaux et Niestlé, 1988. p. 29-44.

SILVA. L. N da; LEAL, T. F. Caracterizando o gênero Carta de Reclamação. In: CONGRESSO DE LEITURA - COLE, 16., 2007, Campinas. Anais... Campinas: Unicamp, 2007.

YUNES, E. Tecendo um leitor: uma rede de fios cruzados. Curitiba: Aymará, 2009. 